\title{
Global perspectives on nursing leadership: Lessons learned from an international nursing and health care leadership development program
}

\author{
Lynda A. Wilson, Elizabeth A. Crooks, W. Sara Day, Martha A. Dawson, C. Ann Gakumo, Doreen C. \\ Harper, Carolynn T. Jones, Karen H. McCarty, Lisa H. Theus
}

School of Nursing, University of Alabama, Birmingham, USA.

Correspondence: Lynda A. Wilson. Address: The University of Alabama at Birmingham School of Nursing, NB 420, 1720 University Boulevard South Birmingham, Alabama 35294-1210, USA. Email: lyndawilson@uab.edu

Received: J une 18, 2013

DOI : $10.5430 /$ jnep.v4n2p140
Accepted: July 29, 2013

Online Published: October 15, 2013

URL: http://dx.doi.org/10.5430/jnep.v4n2p140

\section{Abstract}

Background: Nurses and health care professionals who practice in the global health arena must develop the leadership skills to lead interprofessional teams that direct individual and population-based healthcare, shape health policy, and develop responses to a changing environmental, socioeconomic, and technological landscape. Programs aimed at developing these skills including nurses and health professionals from low and middle resource nations are limited. Since 2008, the Pan American Health Organization (PAHO)/World Health Organization (WHO) Collaborating Center on International Nursing at the University of Alabama at Birmingham (UAB) has offered a biennial International Nursing and Healthcare Leadership Development Program composed of: a) didactic classes; b) mentorship/coaching; c) health/service organization site visits; and d) cultural enrichment. This paper presents program evaluation data from international participants from South America and Africa $(n=69)$, UAB students $(n=13)$, faculty $(n=32)$, and mentors/coaches $(n=$ 45) from programs held from 2008-2012. Implications for future programs aimed at international nursing and healthcare leadership skill development are discussed.

Methods: A mixed methods approach employing investigator-designed surveys at the end of each program was used to collect quantitative and qualitative evaluation data. Questions that guided the program evaluation were: 1) What were participants' perceptions about the extent to which objectives of the leadership classes and overall program were achieved?; 2) What were participants' and faculty mentor/coaches' evaluation of the mentoring/coaching component of the program?; and 3) What were participants' and faculty mentor/coaches' perceptions of program strengths, weaknesses, and need for change? Themes from narrative comments were identified using content analysis procedures and the NVivo9@ qualitative data analysis software package.

Results: Mean scores on all of the quantitative evaluation items ranged from 3.71-4.9 out of 5 possible points indicating very positive perceptions of the program and agreement that objectives had been achieved. Quantitative and qualitative findings suggest that participants were more satisfied with the mentoring/coaching component of the program than were faculty. The primary challenges identified were time limitations and communication difficulties that included both language and information technology barriers. Participants and faculty agreed that program strengths included program content and organization, the ability for cross-cultural interaction with peers, formulation of personal leadership development plans, and mentor/coach engagement. Suggestions for program improvement were aimed at providing 
unstructured time to allow participants to explore their host surroundings, providing sufficient breaks between classes and activities, inclusion of problem-based learning such as case study analysis, and more time allotted to mentor/coach engagement.

Conclusion: The program has been successful in preparing future leaders in nursing and other health-related disciplines to better meet global health needs. The desire of program participants for more time to engage in a mentoring/coaching relationship and free time to experience the host country surroundings suggests that program length is an important influence in participant satisfaction. Even when increased costs are taken into consideration, a 3-week program duration may be more desirable than a 2-week duration. Because communication barriers contributed to participant and faculty dissatisfaction, care should be taken to ensure a basic level of English fluency for all participants if simultaneous translations services aren’t offered is recommended.

\section{Key words}

Global, Leadership, Nursing, Health professionals

\section{I ntroduction}

As the largest segment of the healthcare workforce, nurses play pivotal roles in ensuring global health by directly caring for individuals and communities, shaping policy, influencing and leading interprofessional teams, and responding to environmental, socioeconomic, and technological changes that impact health care delivery. Nurses are often the sole providers for individual patients, families, and communities, particularly in rural and remote areas. The knowledge and skills required to meet these demands are diverse and complex. Therefore, there is an urgent need for programs that focus on developing leadership skills of nurses and other health care professionals emphasizing multicultural understanding, collaboration, problem solving, personal leadership development, and interprofessional team work. Offering programs that include nurses and other health professionals from different countries and healthcare settings also provides an important opportunity for interprofessional collaboration and for sharing best practices and ideas across global borders.

Since 2008, an International Nursing and Healthcare Leadership Development program has been offered biennially to a nurses and other health professionals from both middle and low resource nations by the Pan American Health Organization (PAHO)/World Health Organization (WHO) Collaborating Center on International Nursing at the University of Alabama (UAB) School of Nursing. This paper presents a review of the literature describing other international nursing and health care leadership development programs, describes the development and implementation of the UAB program, presents program evaluation data, and discusses implications for development of similar programs in the future. The specific questions that guided the program evaluation were: (a) What were participants' evaluations of the extent to which the objectives of the leadership classes and overall program were achieved? (b) What were participants' and faculty mentor/coaches' evaluations of the mentoring/coaching component of the program? and (c) What were participants' and faculty mentors'/coaches' perceptions of program strengths, program weaknesses, and recommendations for change?

\section{Literature review}

A review of the literature was conducted to examine published articles, books, and websites that included information in English, described leadership programs for nurses and other healthcare providers, included participants from multiple countries, and provided coaching or mentoring. The search resulted in the identification of four different international leadership programs for nurses and other health professionals. The first two programs were developed by the International Council of Nurses (ICN): The Leadership for Change (LFC) program, and the Global Nursing Leadership Institute (GNLI). The third program was developed by the Pan American Health Organization (PAHO): the Edmundo Granda Ugalde Leaders in International Health Program (LIHP). The fourth program was developed by Sigma Theta Tau, 
International (STTI): The International Leadership Institute (ILI). An article describing a fifth program was recently published describing a Nurse Leadership Development Center that is being inaugurated in Hong Kong in 2013 as a collaborative partnership between the Chinese University of Hong Kong, and the University of British Colombia; there are not yet any data describing the outcomes of this program ${ }^{[1]}$.

In 1995, the ICN developed the LFC program to prepare nurses as strong and effective leaders and managers ${ }^{[2,3]}$. The LFC program aims to complement a country's own education system in order to give nurse leaders the ability to participate in health policy development and decision-making ${ }^{[3]}$. In 2006 the program was expanded to include a "train-the-trainer" component so that ICN-approved trainers could implement the program in their own countries under a licensing agreement with the ICN ${ }^{[2]}$. Over the course of the 2-year program, nurses participate in four workshops that cover five different modules. The program uses action-learning strategies and mentorship, and participants complete team projects and individual development plans. Each year, 30 nurses are selected from a given country to participate in the program. Since 2008, the LFC program has been implemented in nearly 70 countries and many of the countries have implemented the program through ICN's train-the-trainer program ${ }^{[2]}$. Respondents who participated in an evaluation survey have reported sustainable benefits from projects that were developed as part of the program. These projects focused on maternal mortality, quality improvement, HIV and TB training programs, developing a national nurses' association, and developing performance evaluation tools for nurse managers ${ }^{[4,5]}$.

In 2009, the ICN developed the ICN-Burdett GNLI, an annual leadership program for nurses at senior and executive levels in countries across the world. Thirty nurses representing all six WHO regions are selected each year to attend the 6-day program which is held in Geneva, Switzerland. The GNLI is designed for nurses already in high-level leadership positions, as opposed to the LFC that develops nurses at all levels of leadership ${ }^{[6]}$. The GNLI uses action-learning and opportunities for creative problem-solving. To facilitate action-learning during the institute, participants complete a 2-page country profile describing key aspects of nursing and healthcare in their countries. These profiles are then used as a basis for action learning and group discussion as participants identify similarities and differences in leadership challenges, and share ideas about how to address these challenges. Zittell, Ezzeddine, Makatjane, Graham, Luangamornlert, and Pemo ${ }^{\text {[7] }}$ described lessons learned by one of the working groups as they compared their varied experiences and noted that the opportunity provided a "mountaintop experience" (p. 53) as the participants were able to reach out beyond their individual borders. Blaney ${ }^{[6]}$ noted several challenges associated with planning and implementing the GLNI including logistics and costs, as well as the diversity of language and cultural backgrounds. However, Blaney noted that these challenges also provided unique opportunities for global exchange of ideas and strategies for addressing health care problems at home. At the end of the GLNI and again 4-6 months later, participants rated the experience as valuable and as contributing to their leadership development and attainment of their personal goals ${ }^{[6]}$. At the end of the 6-day program, the program was rated as among the top third of development programs they had attended by 77\% of the 2009 cohort and $84 \%$ of the 2010 cohort. The Center for Creative Leadership prepared an extensive evaluation report for the 2009 and 2010 programs, and concluded that participants' viewed the program as helping them to become more effective leaders and that participants' self-ratings of their leadership competencies improved from pre to post-program assessments ${ }^{[8]}$.

Auer and Espinel described outcomes of the Edmundo Granda Ugalde Leaders in International Health Program (LIHP) developed in 2008 by the Pan American Health Organization (PAHO) ${ }^{[9]}$. This 9-month program is offered each year to professionals in the Americas working in public health, international relations, or related fields. The program begins with participants working with PAHO country offices and other health officials in their home countries to identify a project that they subsequently develop during the LIHP. Participants attend an initial 1-week intensive onsite session, and then receive on-going support from the program faculty as they develop and implement their projects in their home countries. The program "promotes the development of a set of knowledge, skills, attitudes, and values associated with international health theory and practice, which have been organized into a system of competencies and are oriented towards ethical principles and the values of equity, solidarity, social justice, and the right to health" ${ }^{[9]}$. The program does on -going process evaluations for program improvement. Since its inception in 2008, the LIHP has been offered to 185 participants 
representing 31 countries. The program has built upon previous leadership programs offered by PAHO to 187 participants. Participants have contributed to the development of 92 projects on priority public health topics ${ }^{[9]}$. An external evaluation conducted in 2010, internal program evaluations, and anecdotal evidence all show the program to be effective in enhancing competencies in international health, global development, and international relationships ${ }^{[9]}$. Further information about this program, and numerous leadership development resources can be found on the LIHP website ${ }^{[10]}$.

The Sigma Theta Tau International Honor Society of Nursing (STTI) offers several different programs through the International Leadership Institute (ILI): Maternal-Child Health Nurse Leadership, North America; Maternal-Child health Nurse Leadership, South Africa (pilot); Geriatric Nursing Leadership; and Nurse Faculty Leadership Academy. The 18-month programs pair nurse participants with mentors and include workshops and online activities. STTI also offers a 2-day Leadership Academy workshop, and the Leadership Development Center, an interactive tool that supports professional development of leaders. Information about the various programs is available at the STTI website, although no publications were identified that described program outcomes ${ }^{[11]}$.

All four programs are open to nurses and/or other health professionals across the world and aim to improve leadership skills. However, each program is uniquely designed and has implemented various methods of evaluation. Three of the programs are long-term, lasting 9 months (the PAHO LIHP), 18 months (the STTI ILI programs), or 2 years (the ICN LFC program). The ICN GLNI lasts for 6 days; however participants are encouraged to continue networking after the end of the program. All of the programs have received varying levels of financial support to reduce the economic costs for program participants. Available evaluation data suggests that the programs have been perceived positively by participants, and that projects developed through the programs have had positive impacts on the health systems of participants' home countries.

\section{The international nursing and healthcare leadership program at UAB}

The first international nursing and healthcare leadership program at UAB was offered in 2008, and subsequent programs have been offered in 2010 and 2012. The program has evolved as we have reviewed evaluation data and feedback from participants and from faculty who have served as mentors and/or coaches. The program's objectives have been refined slightly, although the primary focus has not changed. The objectives for the 2012 program were to: (a) strengthen nursing leadership capacity; (b) enhance child and family health through innovative nursing care delivery programs; and (c) promote ongoing collaboration on projects to strengthen global nursing and health care delivery. The 2008 program was offered only to nurses in Latin America, since a primary focus of the UAB PAHO/WHO Collaborating Center was strengthening child and family nursing in that region. In 2010 and 2012 the program was expanded to also include nurses and other health professionals from Zambia because UAB had a number of ongoing projects in that country. The primary eligibility criteria included a basic level of fluency in written and spoken English (based on self-report), working as a nurse or health professional from a Latin American country or from Zambia, and a letter of support from the participant's employer granting permission for the participant to attend the program. The program is offered in English, and participants must have a basic level of proficiency in written and spoken English. International participants for whom English is a second language also had the opportunity to take professional English classes to improve verbal and written language at the UAB English Language and Culture Institute (ECLI) prior to or in conjunction with the leadership program.

\section{Description of the program}

The program included four basic components: (a) didactic classes focused on nursing and health care leadership; (b) mentorship and coaching; (c) site visits to healthcare and service organizations; and (d) academic enrichment and cultural activities. The didactic classes were also open to UAB undergraduate or graduate students in the health professions as a 3-credit elective course, providing students with a rich global and cross-cultural learning experience. 
UAB's program is based on an adaptation of the conceptual model of leadership that guided the International Council of Nurses' Leadership for Change (LFC) Program ${ }^{[5]}$. The LFC program is based on the concept that: "Effective leaders look beyond their immediate boundaries and work environments. They assess potential impacts on health as well as on the health sector...They are aware of helping and hindering factors that influence the health sector and nursing, and develop appropriate strategies. They seek and maintain networks and partnerships in the broader environment” ${ }^{\text {[5] }}$. The LFC model is based on the assumption that all nurses can be leaders, and that leadership is influenced by characteristics of the leader as well as characteristics of the followers and the environment. The UAB program built on the key elements of leadership that were addressed in the LFC model including: vision and strategic thinking; external awareness; influence; motivation; confidence; trust political skill review, change, and renewal of self and others; and teamwork and strategic alliances ${ }^{[5]}$, expanding these concepts to the program objectives (see Figure 1).

In 2008 and 2010, the program was 3 weeks long and integrated the English classes with the other activities. In 2012, the English classes were offered as an option for 1 intensive week prior to the beginning of the leadership program, which was reduced to 2 weeks in order to reduce the time that participants would need to be away from their work and families. In 2008 and 2010, participants were offered the opportunity to stay with volunteer host families in the community, adding to their cross-cultural experience. Because many host families had provided housing to international visitors participating in a different program hosted by the UAB School of Nursing in 2011, the 2012 participants stayed in university housing during the program. Housing arrangements allowed cross cultural relationship building to emerge in a non-structured social environment. The initial 2008 program was offered in January, but in 2010 and 2012 the program was offered in July to better facilitate faculty and participant immersion. A videotape describing the 2010 program is available at: http://www.uab.edu/nursing/home/international-affairs-home/intl-nursing-leadership-prog.

Global perspectives on nursing and healthcare leadership didactic classes. Figure 1 provides a comparison of the major topics and objectives addressed during the leadership classes for each of the 3 program years. The class is open to undergraduate, graduate, and non-degree-seeking students as an elective, and is taught by faculty from nursing and from other schools on campus including the Schools of Health Professions, Medicine, and Public Health. The course curriculum encourages active onsite participation, and sharing of experiences and ideas between course participants, faculty coaches, and course faculty.

Objectives (remained the same for all 3 program offerings)

- Describe characteristics of global health care leaders

- Analyze selected theories of leadership

- $\quad$ Propose strategies to develop global health care leaders

- Evaluate own style of leadership including strengths and areas for improvement

- Identify national and international organizations that might provide resources for health care leaders

- $\quad$ Prepare a personal leadership development plan related to implementation of projects to improve health and/or influence health policy at the local, national, or global level.

Course Topics

- $\quad$ Leadership theories and frameworks - all years

- $\quad$ Program planning and monitoring - all years

- Innovative strategies in health care problem solving - all years

- $\quad$ Principles of mentoring - 2008 and 2010

- $\quad$ Principles of coaching - 2012

- $\quad$ SWOT analyses and developing personal leadership development plans - 2010 and 2012

- $\quad$ Power, conflict management, and team building - 2012

Figure 1. Objectives and Topics of the Leadership Class 
Mentorship and coaching. Time was scheduled during each program for participants to meet with UAB faculty who had volunteered to serve as mentors or coaches. In the 2008 program, participants were paired with UAB nursing faculty mentors and were asked to develop proposals for collaborative projects that they could implement in their home countries to improve health care. We changed this requirement in 2010 because program evaluation data indicated that many participants were unable to complete their projects due to time demands when they returned home. In 2010, we focused on partnering faculty mentors with participants to help them develop personal leadership plans and suggested that mentors maintain communication with participants for 1 year after the end of the program. However many times this communication was a challenge, so in 2012 we changed the focus to developing "coaching” teams, pairing 2-3 faculty members with 5-6 participants. The teams focused on supporting each participant as they developed a personal leadership development plan during the 2-week program. The decision about whether the teams would maintain communication after the program was left up to each individual. We adapted a coaching model developed by Coaching the Global Village ${ }^{[12]}$. To support the coaching process, each participant submitted a professional strength, weakness, opportunity and threat (SWOT) analysis prior to their arrival to facilitate their individual leadership development planning.

Other program activities. Visits to local health facilities were arranged in order to accommodate particular interests of participants. Participants have also visited a program that provides training in community development and self-help skills, and participated in meetings of the local chapter of the Alabama State Nurses Association. Participants had many opportunities to learn first-hand about U.S. and Alabama culture through activities that included living with host families (in 2008 and 2010), visiting homes of other students and faculty, attending church services, visiting museums, attending dances and musical performances, and, of course, shopping! One particularly meaningful activity was a visit to the Birmingham Civil Rights Institute, which documents the civil rights struggle in the U.S. and globally.

Program costs. Mindful of the personal gross income of nurses in low resource countries, deliberate business planning was based on creating realistic charges for participants in the international program. Program costs were established to engage nurses from low resource countries as program participants, and to enable them to seek support from their academic and health care service organizations. A modest tuition and fee structure for the international leadership program was established to support the most basic infrastructure costs of the program, including health care clearance and insurance, processing fees, on-line access, food and transportation costs, and the English Language and Cultural Institute if applicable. Additionally, grant, in-kind and philanthropic donations were secured to support program costs over the past three offerings. Given the program's progressive growth and success in recruiting nurse participants during the past three programs, we believe the program tuition and fees are representative of the gross income of the nursing workforce among the represented countries.

\section{Program evaluation and outcomes}

\section{Description of participants}

Program participants have come from eight countries: Brazil, Chile Colombia, Costa Rica, Honduras, Mexico, Peru and Zambia. Participants have included male and female nurses and other health professionals. Participants' ages ranged from 22 to 55 providing an excellent platform for inter-generational learning. Faculty participants represented different generations in clinical and non-clinical specialties. Faculty provided classroom instruction, coordinated agency sites visits, and served as mentors or coaches. UAB students were able to enroll in the leadership course and receive academic credit, or serve as volunteers to assist with program implementation. Table 1 provides information about the international leadership program participants, faculty mentors/coaches, faculty teaching in the leadership course, and students enrolling in the leadership course for the 2008, 2010, and 2012 programs. 
Table 1. Number of Participants, Faculty, and Students by Year of Program

\begin{tabular}{|c|c|c|c|}
\hline Category of Participant & 2008 Program & 2010 Program & 2012 Program \\
\hline International Participants & $\begin{array}{l}18 \text { nurses ( } 8 \text { from Brazil, } 3 \\
\text { from Chile, } 1 \text { from Colombia, } \\
\text { and } 6 \text { from Honduras) }\end{array}$ & $\begin{array}{l}25 \text { nurses (12 from } \\
\text { Zambia, } 3 \text { from } \\
\text { Brazil, } 3 \text { from Chile, } \\
1 \text { from Costa Rica, } 3 \\
\text { from Honduras, and } 3 \\
\text { from Peru) }\end{array}$ & $\begin{array}{l}26 \text { participants (20 from } \\
\text { Zambia including } 15 \\
\text { nurses and } 11 \text { clinical } \\
\text { officers; } 1 \text { from Mexico, } \\
1 \text { from Costa Rica, and } 4 \\
\text { from Brazil) }\end{array}$ \\
\hline Faculty Teaching in Leadership Class & 6 & 13 & 13 \\
\hline Faculty Mentors or Coaches & 18 & 15 & 12 \\
\hline Students Enrolling in Leadership Class & $\begin{array}{l}8 \text { undergraduate and } 5 \\
\text { graduate students }\end{array}$ & $\begin{array}{l}3 \text { undergraduate and } 7 \\
\text { graduate students }\end{array}$ & $\begin{array}{l}2 \text { undergraduate and } 7 \\
\text { graduate students }\end{array}$ \\
\hline
\end{tabular}

\section{Participants' and faculty mentors'/ coaches' evaluations of the program}

Program participants and faculty mentors/coaches completed investigator-designed surveys at the end of each program rating the program objectives and activities on a 5 -point Likert scale (with $1=$ low and $5=$ high), and also provided open-ended comments about program strengths and recommended improvements. These surveys had face validity but there was no assessment of their reliability. The themes from narrative comments were identified using content analysis procedures and the NVivo9@ qualitative data analysis software package. Surveys were sent to the 2008 and 2010 participants and faculty collaborators 1 year after the program in an attempt to gather longer-term outcome data, however the response rate was too low to be reported. Table 2 presents the means from the participants' quantitative surveys, and Table 3 summarizes the major themes that emerged from their qualitative comments. Tables 4 and 5 present data from the faculty quantitative evaluations and from their qualitative comments.

Table 2. Participant Mean Evaluations of Extent to Program Goals and Leadership Class Objectives were Met, and of Satisfaction Working with Mentor/Coach

\begin{tabular}{|c|c|c|c|}
\hline Program Component & $\begin{array}{l}2008 \text { Mean } \\
(n=16)\end{array}$ & $\begin{array}{l}2010 \text { Mean } \\
(n=25)\end{array}$ & $\begin{array}{l}2012 \text { Mean } \\
(\mathrm{n}=25)\end{array}$ \\
\hline \multicolumn{4}{|l|}{ Overall Program Goals } \\
\hline Strengthen nursing leadership capacity & 4.7 & 4.6 & 4.72 \\
\hline $\begin{array}{l}\text { Enhance child and family health through innovative nursing care delivery } \\
\text { programs }\end{array}$ & 4.4 & 3.92 & 4.24 \\
\hline Enhance written and spoken English skills to promote leadership development & 4.8 & 4.3 & 4.09 \\
\hline $\begin{array}{l}\text { Promote ongoing collaboration on projects to strengthen global nursing and } \\
\text { health care delivery }\end{array}$ & 4.9 & 4.68 & $\mathrm{n} / \mathrm{a}$ \\
\hline \multicolumn{4}{|l|}{ Leadership Class Objectives } \\
\hline Describe characteristics of global nursing leaders & 4.75 & 4.54 & 4.68 \\
\hline Describe selected theories of leadership & 4.3 & 4.5 & 4.78 \\
\hline Describe strategies to develop global nursing leaders & 4.4 & 4.58 & 4.76 \\
\hline Evaluate own style of leadership including strengths and areas for improvement & 4.4 & 4.25 & 4.83 \\
\hline $\begin{array}{l}\text { Identify national and international organizations that might provide resources for } \\
\text { nursing leaders }\end{array}$ & 4.4 & 3.71 & 4.38 \\
\hline $\begin{array}{l}\text { Prepare a personal plan for the development of personal leadership related to } \\
\text { implementation of projects to improve health }\end{array}$ & 4.3 & 4.54 & 4.88 \\
\hline \multicolumn{4}{|l|}{ Participants’ Level of Satisfaction in Working with Mentor/Coach } \\
\hline The match between my interests and the interests of my collaborating partner & 4.7 & 4.83 & 4.65 \\
\hline The amount of time I spent with my collaborating partner & 4.4 & 4.36 & 4.08 \\
\hline My ability to communicate easily with my collaborating partner & 4.5 & 4.56 & 4.58 \\
\hline $\begin{array}{l}\text { The progress on our collaborative project (Changed in } 2010 \text { to Progress on } \\
\text { Development of Personal Leadership Plan) }\end{array}$ & 4.5 & 4.52 & 4.50 \\
\hline
\end{tabular}

Note. Rating Scale 1-5, 5 is highest 
Table 3. Summary of Themes from Participants' Qualitative Comments about Program Aspects Enjoyed the Most, Enjoyed the Least, and Suggested Improvements

\begin{tabular}{|c|c|c|c|c|c|}
\hline \multirow{2}{*}{ Items } & \multicolumn{4}{|c|}{ Frequency Coded } & \multirow{2}{*}{ Example of Comments } \\
\hline & 2008 & 2010 & 2012 & Total & \\
\hline \multicolumn{6}{|l|}{ Aspects Enjoyed the Most } \\
\hline Class and Program Content & 13 & 16 & 16 & 45 & "Strategic planning and SWOT analysis classes" \\
\hline $\begin{array}{l}\text { Program Planning, Organization, } \\
\text { and Infrastructure }\end{array}$ & 7 & 7 & 4 & 18 & $\begin{array}{l}\text { "Organization and communication with students } \\
\text { before and throughout the program" }\end{array}$ \\
\hline $\begin{array}{l}\text { Cultural, Social, and Academic } \\
\text { Enrichment Experiences }\end{array}$ & 4 & 4 & 6 & 14 & $\begin{array}{l}\text { "Cultural, social, and academic enrichment } \\
\text { experiences" }\end{array}$ \\
\hline Interactions with Others & 4 & 5 & 2 & 11 & $\begin{array}{l}\text { "Participants' interaction and knowing other } \\
\text { hospitals, cultures, and people" }\end{array}$ \\
\hline Mentoring or coaching & 4 & 5 & 1 & 10 & "The interaction with my project collaborator" \\
\hline Hospitality and friendliness & 6 & 3 & 1 & 10 & "Everyone was engaged and helped us" \\
\hline Development of Leadership Plan & NA & 2 & 8 & 10 & "Personal plan based on SWOT analysis" \\
\hline $\begin{array}{l}\text { Language Classes and } \\
\text { Experiences }\end{array}$ & 6 & 3 & NA & 9 & $\begin{array}{l}\text { "I liked the grammar, spelling, and vocabulary } \\
\text { classes" }\end{array}$ \\
\hline Collaborative Project & 6 & NA & NA & 6 & $\begin{array}{l}\text { "Working with mentors and the chance to continue to } \\
\text { work with them to develop my project" }\end{array}$ \\
\hline \multicolumn{6}{|l|}{ Aspects Enjoyed the Least } \\
\hline $\begin{array}{l}\text { Problems with Infrastructure or } \\
\text { Program Management }\end{array}$ & 11 & 4 & 2 & 17 & "Insufficient time for all activities" \\
\hline Class or Presentation Content & 2 & 3 & 2 & 7 & $\begin{array}{l}\text { "Some presentations about programs that I am not } \\
\text { involved with as much" }\end{array}$ \\
\hline $\begin{array}{l}\text { Interaction and Cultural } \\
\text { Challenges }\end{array}$ & 0 & 1 & 4 & 5 & $\begin{array}{l}\text { "Some classes focused on the Zambian group and we } \\
\text { Latinos did not understand the jokes and comments" }\end{array}$ \\
\hline $\begin{array}{l}\text { Communication or Language } \\
\text { Barriers }\end{array}$ & 2 & 1 & 1 & 4 & "The biggest barrier was the language" \\
\hline $\begin{array}{l}\text { Insufficient Opportunity for } \\
\text { Desired Activities }\end{array}$ & 3 & 1 & 0 & 4 & "Leave lunches free from meetings" \\
\hline \multicolumn{6}{|l|}{ Suggested Improvements } \\
\hline $\begin{array}{l}\text { Program Planning and } \\
\text { Management Changes }\end{array}$ & 12 & 22 & 13 & 47 & "Provide more free time and more time with mentors" \\
\hline $\begin{array}{l}\text { Provide Additional Activities or } \\
\text { Content }\end{array}$ & 9 & 11 & 7 & 27 & $\begin{array}{l}\text { "Would have liked longer program and time to visit } \\
\text { rural communities" }\end{array}$ \\
\hline $\begin{array}{l}\text { Recommended Changes in } \\
\text { Teaching Strategies }\end{array}$ & 0 & 3 & 5 & 8 & "Use more case analysis and active teaching" \\
\hline $\begin{array}{l}\text { Require Minimal English } \\
\text { Proficiency }\end{array}$ & 5 & 1 & 1 & 7 & $\begin{array}{l}\text { "Require that all participants have the same level of } \\
\text { English" }\end{array}$ \\
\hline $\begin{array}{l}\text { Recommended Changes Related } \\
\text { to Coaching }\end{array}$ & NA & NA & 4 & 4 & "Need more time with coaches" \\
\hline
\end{tabular}

Table 4. Faculty Evaluations of Mentoring or Coaching Partnerships

\begin{tabular}{|c|c|c|c|}
\hline Item & $\begin{array}{l}2008 \\
(n=11)\end{array}$ & $\begin{array}{l}2010 \\
(n=20)\end{array}$ & $\begin{array}{l}2012 \\
(n=10)\end{array}$ \\
\hline Ability to Communicate & 3.2 & 3.8 & 4.8 \\
\hline Availability of Collaborator & 4.3 & 4.6 & 4.4 \\
\hline Responsiveness of Collaborator to Requests for Information & 4.8 & 4.6 & 4.9 \\
\hline Amount of Time spent in Communication with Collaborator & 4.0 & 4.5 & 3.9 \\
\hline
\end{tabular}

Note. Rating Scale 1-5, 5 is highest 
Table 5. Summary of Themes from Faculty Mentors'/Coaches' Qualitative Comments about Program Aspects Enjoyed the Most, Enjoyed the Least, and Suggested Improvements

\begin{tabular}{|c|c|c|c|c|c|}
\hline \multirow{2}{*}{ Items } & \multicolumn{4}{|c|}{ Frequency Coded } & \multirow{2}{*}{ Example of Comment } \\
\hline & 2008 & 2010 & 2012 & Total & \\
\hline \multicolumn{6}{|l|}{ Aspects Enjoyed the Most } \\
\hline $\begin{array}{l}\text { Opportunities to Interact with Other } \\
\text { Cultures }\end{array}$ & 7 & 11 & 2 & 20 & $\begin{array}{l}\text { "The opportunity to work closely with a } \\
\text { colleague from a different cultural background" }\end{array}$ \\
\hline Specific Participant Qualities & 8 & 7 & 3 & 18 & "She was very dedicated to her project" \\
\hline Similar Interests As Participants & 3 & 2 & 0 & 5 & “Well matched faculty and participant” \\
\hline Opportunity To Make a Difference & 1 & 4 & 0 & 5 & "To improve care of children in Brazil" \\
\hline Other & 4 & 2 & 3 & 9 & “Ability to develop long-term collaborations" \\
\hline \multicolumn{6}{|l|}{ Aspects Enjoyed the Least } \\
\hline Time Demands and Constraints & 5 & 1 & 6 & 12 & $\begin{array}{l}\text { "Scheduling was a nightmare; limited time to } \\
\text { meet in two weeks" }\end{array}$ \\
\hline $\begin{array}{l}\text { Unclear Roles for Mentor and } \\
\text { Mentee }\end{array}$ & 1 & 3 & 0 & 4 & $\begin{array}{l}\text { "Unclear goals/expectations of mentor at the } \\
\text { beginning" }\end{array}$ \\
\hline $\begin{array}{l}\text { Difficulty with Communication } \\
\text { During and After Workshop }\end{array}$ & 9 & 3 & 0 & 12 & "Language gap" \\
\hline Other & 6 & 3 & 0 & 9 & $\begin{array}{l}\text { "Limited experience in my mentee's area of } \\
\text { interest” }\end{array}$ \\
\hline Suggested Improvements & & & & & \\
\hline $\begin{array}{l}\text { More Careful Planning and } \\
\text { Facilitation of Communication with } \\
\text { Mentees }\end{array}$ & 2 & 5 & 1 & 8 & $\begin{array}{l}\text { "Meeting of all faculty collaborators to discuss } \\
\text { what strategies worked and share" }\end{array}$ \\
\hline Other Suggestions & 6 & 2 & 0 & 8 & $\begin{array}{l}\text { "Program should supply participants with } \\
\text { computer headsets ...to stimulate follow-up } \\
\text { (communication)" }\end{array}$ \\
\hline
\end{tabular}

Participants’ perceptions about leadership classes and overall program. The first question for the program evaluation was "What were participants' perceptions about the extent to which objectives of the leadership classes and the overall program were achieved?" Mean scores on all of the quantitative evaluation items ranged from 3.71-4.9 (measured on a 5-point Likert scale with 5 reflecting high ratings), indicating very positive perceptions of the program and agreement that objectives had been achieved.

Participants' and mentors'/coaches' evaluations of mentoring/coaching. The second question guiding the program evaluation was 'What were participants' and faculty mentor/coaches' evaluations of the mentoring/coaching component of the program?” Mean scores on the items assessing the mentoring/coaching ranged from 4.08-4.83 for program participants, and from 2.67-5.2 for the faculty. These findings suggest that the program participants were more satisfied with the mentoring/coaching than were faculty. The lowest scores for the faculty related to items addressing ability to communicate with the program participant, and amount of time available for the mentoring/coaching interactions. The faculty ratings of ability to communicate with program participants were lower in 2008 and 2010 when there were more Latin American participants who experienced challenges with English. In 2012, a major challenge identified was the limited amount of time available to spend with the coaching teams. The length of the program was decreased in 2012 from a 3-week program (offered in 2008 and 2010) to a 2 week program. These findings suggest the need to consider re-expanding the program to 3 weeks and providing more free time and more time for interactions with the coaching teams.

Evaluations of program strengths, weaknesses, and recommended changes. The third question that guided the program evaluation was 'What were participants' and faculty mentors'/coaches' perceptions of program strengths, program weaknesses, and recommendations for change?” Themes identified from participants' qualitative comments 148

ISSN 1925-4040 E-ISSN 1925-4059 
related to each of these categories were identified using content analysis procedures and the NVivo9 software package. The frequency with which each code was identified during the 2008, 2010, and 2012 programs is listed in Table 3. Even though there were different numbers of participants each year, the counts provide some indication of the relative frequency with which the themes were mentioned. The findings from these qualitative analyses indicated that aspects of the program most enjoyed by participants were related to specific content (e.g. strategic planning and individual leadership analyses), program organization, and interactions with other participants and coaches. The aspects of the program that they enjoyed the least focused primarily on insufficient free time and insufficient time with coaches. Participants from Latin America also identified communication challenges. The most frequently mentioned suggestions for program improvement included providing more unstructured time to pursue individual goals, and extending the length of the program.

The qualitative comments from faculty support the quantitative findings, suggesting that the most positive aspect of the program for faculty was the opportunity to develop collaborative or coaching partnerships with colleagues from other cultures. The qualitative comments also suggested that time constraints, competing demands related to their other responsibilities, and communication problems were perceived barriers. The faculty identified several specific suggestions for improving future programs that we will integrate as we plan our next program: providing more clear orientation and guidelines about expectations for coaches and coaching teams, providing opportunities for faculty to share lessons learned and strategies with one another, and identifying ways to facilitate more specific time for meetings with the coaching teams.

\section{Discussion}

Since its inception, the primary goal of the International Nursing and Health Care Leadership Program has been to prepare future leaders in nursing and other health-related disciplines to better meet global health care needs. The program provided an excellent opportunity for participants, faculty, and students to learn from each other. In addition, the program has provided opportunities for UAB undergraduate and graduate students to interact with global nursing and health leaders. Findings from participant and faculty evaluations have been used to revise and strengthen the program with each offering, although overall the evaluation data suggest that the program goals have been achieved.

\section{Program limitations}

This program evaluation was limited by the lack of data collected after participants' returned to their home countries. Although we were able to measure the program's overall effectiveness from both participants and faculty responses completed at the end of the onsite program, more long-term data on program outcomes and impact is needed. Despite this limitation, evaluation data have provided useful information that has guided ongoing revisions and improvements in the program. Another limitation was the lack of validity or reliability assessment of the data collection instruments, although these instruments were developed specifically to evaluate the extent to which program objectives had been met, and had face validity.

\section{Program strengths, challenges, and suggestions for improvement}

Participants' evaluations of achievement of program objectives. The first question that guided the program evaluation focused on participants' evaluations of the extent to which the objectives of the overall program and of the specific leadership classes were achieved. Mean scores across all three program offerings on each of the quantitative evaluation items ranged from 3.71 to 4.75 , reflecting strong and positive evaluations. This finding is similar to the results of the end-of-program ratings reported for the GNLI program offered by the ICN ${ }^{[6]}$. Unlike the evaluation of the UAB program, The GNLI evaluation also included pre- and post-program assessments of participants' perceptions of their achievement of 20 leadership competencies, as well as assessments completed 4-6 months after completion of the program ${ }^{[8]}$. The evaluation of the current program would have been strengthened by having similar assessments, and future programs will incorporate these evaluation strategies. 
Participants' and faculty evaluations of mentoring/coaching. The second question guiding the program evaluation addressed perceptions of participants and faculty about the mentoring/coaching component of the program. The findings suggested that participants were highly satisfied with the mentoring and coaching, although faculty perceived challenges related to communication with program participants (particularly in 2008 and 2010 when there were more Latin American participants who had limited English proficiency). In 2012, faculty scores also reflected lower levels of satisfaction related to the limited amount of time available for the mentoring/coaching interactions. No other studies were identified in the literature review that reported specifically on levels of satisfaction with mentors or coaches in nursing leadership programs.

Participants' and faculty perceptions of program strengths, weaknesses, and suggested improvements. The third question that guided the program evaluation focused on assessing participants' and faculty members' perceptions of program strengths, weaknesses, and suggested improvements. Overall, the strengths that were identified included the specific content of the program, its organization, and interactions with peers and faculty coaches. The areas that needed the most improvement were providing more time to spend with coaches and allowing more unstructured time.

\section{Similarities and differences between the program at UAB and other international leadership development programs}

The International Nursing and Health Care Leadership Program at UAB shares some similarities and differences with other programs described in the literature review. Similar to the two programs sponsored by the International Council of Nurses (LFC and GNLI), as well as the International Leadership Institute offered by Sigma Theta Tau International, the initial program in 2008 focused solely on nurses (i.e., nurses from Latin America). However, due to growing collaborations and projects in Zambia, this focus expanded to include other health professionals that could stand to benefit from such a program. Unlike the GNLI which was designed for nurses already in leadership positions, previous leadership skills, previous leadership skills were not a necessary prerequisite for nurses and health professionals interested in the program. Thus, the UAB program offers leadership development opportunities for nurses at all levels.

The primary objectives of the UAB program differ somewhat from other international leadership programs. Although strengthening the capability of nurse leaders is a shared common goal amongst the programs, the International Nursing Leadership program at UAB has a strong emphasis on the delivery of health care for nurses and health professionals who are on the frontlines of care to individuals and their families. The amount of time required also differed from previous programs. The review of literature showed that programs varied in length from 6 days to 2 years including both onsite and long-distance engagement components. The UAB program lasted for a 2- to 3-week period (3 weeks in 2008 and 2010 and 2 weeks in 2012). This may have created challenges in terms of maintaining longer-term collaborations among participants and with faculty mentors and coaches. However, meeting for a shorter period was more feasible for participants who had families and job responsibilities at home, and helped to reduce overall program costs. Also, the condensed time frame promoted a more work-intensive environment.

\section{Summary of program strengths and areas for improvement}

A major program strength is the opportunity it afforded for cross-cultural sharing as participants assessed their strengths, weaknesses, opportunities and threats and formulated their personal leadership development plans in collaboration with faculty and coaching teams. Another strength is the opportunity for interdisciplinary learning and collaboration with UAB faculty from a variety of disciplines and, starting in 2012, with participants representing diverse health professions.

Language barriers and time constraints were the greatest challenge. It is important to ensure a basic level of English fluency for all participants if the program is to be taught in English and if there are no resources to provide simultaneous translation services. Future programs should also ensure that there is sufficient time for interactions with coaching teams and for sufficient unstructured time to allow participants to focus on their individualized goals. 
In the initial 2008 program, participants worked with faculty mentors to develop collaborative projects designed to improve some aspect of nursing education or health care in participants' countries. Although participants and faculty were enthusiastic about these projects during the onsite program in Alabama, many experienced challenges in implementing their projects when they returned home and encountered competing demands on their time. Therefore, in 2010, the focus changed from developing collaborative projects to working with mentors on individual leadership development plans. In 2012, this approach was further refined as we moved from a mentoring to a coaching model, and participants worked with faculty and with 3-5 other participants in coaching teams on their leadership development plans. Participant evaluations about the coaching teams were positive, although many commented that they would have preferred more time to work in these teams.

Maintaining communication between faculty and program participants after the program's completion was often difficult due to competing time demands as well as internet challenges. Because of the challenges in maintaining long-term interactions after the end of the program (since participants did not have any funding to provide release time from their other work responsibilities), implementation of collaborative projects or maintenance of longer term relationships with mentors and coaches should be optional.

A prerequisite for the development and implementation of this type of leadership program is administrative support and resource allocation based on the fiscal, human and facility resources needed. The UAB School of Nursing has endorsed a strategic plan that includes advancing global leadership among our students, faculty, community, and alumnae. This plan provides the foundation for program support and the program is supported by donated resources that offset overall program costs. Involvement of host faculty in such programs is critical and often requires voluntary service commitment in order to ensure that there is sufficient time for faculty dedicated to the program. Strategies to sustain faculty engagement include providing recognition of their contributions through letters of appreciation, notices in school newsletters and websites, recognition in faculty annual evaluations and when possible providing incentives, or workload release time particularly for program coordination of on-site activities.

\section{Plans for future}

Plans for future program development are to continue to offer the program for health professionals every 2 years in the "even" numbered years. Based on the positive evaluations received from the health professionals and by the growing interest among health professional students in global health, we are also exploring the possibility of offering a similar program for health professional students every 2 years during the "odd" numbered years. We plan to improve the evaluation of future programs by collecting pre- and post-program assessments of participants' perceptions of their leadership competencies, and also by collecting longer-term follow-up data to determine the impact of the program on participants' professional development. Finally, because there may be many nurses and health professionals in the United States with an interest in learning from global colleagues, we plan to expand recruitment of program participants to include nurses as well as other health professionals from all countries, including the United States.

\section{References}

[1] MacPhee, M., et al. Global health care leadership development: Trends to consider. Journal of Healthcare Leadership. 2013; 5: 21-29. http://dx.doi.org/10.2147/JHL.S23010

[2] Anazor, C., Preparing nurse leaders for global health reforms. Nursing Management - UK. 2012; 19(4): 26-28. PMid:22900384 http://dx.doi.org/10.7748/nm2012.07.19.4.26.c9167

[3] Ferguson, S., Developing nurse leaders for today and tomorrow. Nursing Management. 2004; 10(9): 8-9.

[4] Ferguson, S.L., Thriving while working on the edge: nurses leading change worldwide. International Nursing Review. 2008; 55(4): 367-368. PMid:19146541 http://dx.doi.org/10.1111/j.1466-7657.2008.00690.x

[5] Shaw, S., International Council of Nurses: Nursing leadership. 2007, Oxford, UK: Wiley-Blackwell. 232.

[6] Blaney, P., Senior nursing leadership - capacity building at the global level. International Nursing Review. 2012; 59(1): 40-47. http://dx.doi.org/10.1111/j.1466-7657.2011.00953.x

Published by Sciedu Press 
[7] Zittel, B., et al., Divergence and convergence in nursing and health care among six countries participating in ICN's 2010 Global Nursing Leadership Institute. International Nursing Review. 2012; 59(1): 48-54. http://dx.doi.org/10.1111/j.1466-7657.2011.00952.x

[8] Center for Creative Leadership, International Nursing Leadership Institute: The Evaluation Report for 2009 and 2010 Cohorts, International Council of Nurses, Editor 2011, International Council of Nurses: Geneva, Switzerland.

[9] Auer, A. and J.E.G. Espinel, The Pan American Health Organization and international health: A history of training, conceptualization, and collective development. Pan American Journal of Public Health (Revista Panamericana Salud Publica), 2011; 30(2): 122-132.

[10] Pan American Health Organization. Leaders in International Health Program: Edmundo Granda Ugalde. 2013 [cited 2013 May 5]; Available from: http://new.paho.org/hq/index.php?option=com_content\&view=category\&layout=blog\&id=1939\&Itemid=3499\&lang=en .

[11] Sigma Theta Tau, I. International Leadership Institute. 2013 [cited 2013 May 5]; Available from: http://www.nursingsociety.org/LeadershipInstitute/Pages/default.aspx.

[12] Coaching the Global Village. Coaching the global village. 2013 [cited 2013 February 15]; Available from: http://coachingtheglobalvillage.org/. 